OPEN ACCESS

Edited by:

Junhua Peng,

Center for Life Sci\&Tech of China National Seed Group Co. Ltd., China

Reviewed by:

Jinfa Zhang,

New Mexico State University,

United States

Hiroshi Hisano,

Okayama University, Japan

*Correspondence:

Martin J. Wubben

martin.wubben@ars.usda.gov

${ }^{\dagger}$ These authors have contributed equally to this work.

Specialty section:

This article was submitted to

Plant Biotechnology,

a section of the journal

Frontiers in Plant Science

Received: 11 April 2017 Accepted: 03 July 2017

Published: 24 July 2017

Citation:

Geng L, Deng DD, Wubben MJ, Jenkins JN, McCarty JC Jr. and Abdurakhmonov I (2017)

A High-Throughput Standard

PCR-Based Genotyping Method for Determining Transgene Zygosity

in Segregating Plant Populations.

Front. Plant Sci. 8:1252.

doi: 10.3389/fpls.2017.01252

\section{A High-Throughput Standard PCR-Based Genotyping Method for Determining Transgene Zygosity in Segregating Plant Populations}

\author{
Lige Geng ${ }^{1 t}$, Dewayne D. Deng ${ }^{2 \dagger}$, Martin J. Wubben ${ }^{2 *}$, Johnie N. Jenkins ${ }^{2}$, \\ Jack C. McCarty Jr. ${ }^{2}$ and Ibrokhim Abdurakhmonov ${ }^{3}$
}

\begin{abstract}
${ }^{1}$ Hebei Center for Agriculture Genetic Resources Preservation, Institute of Cereal and Oil Crops, Hebei Academy of Agriculture and Forestry Sciences/Crop Genetics and Breeding Laboratory of Hebei Province, Shijiazhuang, China, ${ }^{2}$ Crop Science Research Laboratory, Genetics and Sustainable Agriculture Research Unit, United States Department of Agriculture - Agricultural Research Service, Mississippi State, MS, United States, ${ }^{3}$ Center of Genomics and Bioinformatics, Academy of Sciences of Uzbekistan, Tashkent, Uzbekistan
\end{abstract}

In crop research programs that implement transgene-based strategies for trait improvement it is necessary to distinguish between transgene homozygous and hemizygous individuals in segregating populations. Direct methods for determining transgene zygosity are technically challenging, expensive, and require specialized equipment. In this report, we describe a standard PCR-based protocol coupled with capillary electrophoresis that can identify transgene homozygous and hemizygous individuals in a segregating population without knowledge of transgene insertion site. PCR primers were designed to amplify conserved T-DNA segments of the $35 \mathrm{~S}$ promoter, OCS terminator, and NPTII kanamycin resistance gene in the pHellsgate8 RNAi construct for the Gossypium hirsutum phytochrome A1 gene. Using an optimized multiplexed reaction mixture and an amplification program of only 10 cycles we could discriminate between transgene homozygous and hemizygous cotton control DNA samples based on PCR product peak characteristics gathered by capillary electrophoresis. The protocol was refined by evaluating segregating transgenic progeny from nine $\mathrm{BC}_{1} \mathrm{~S}_{1}$ populations derived from crosses between the transgenic cotton parent 'E-1-7-6' and other cotton cultivars. OCS PCR product peak height and peak area, normalized by amplification of the native cotton gene GhUBC1, revealed clear bimodal distributions of OCS product characteristics for each $\mathrm{BC}_{1} \mathrm{~S}_{1}$ population indicating the presence of homozygous and hemizygous clusters which was further confirmed via $\mathrm{K}$-means clustering. $\mathrm{BC}_{1} \mathrm{~S}_{1}$ plants identified as homozygous or hemizygous were self-fertilized to produce $\mathrm{BC}_{1} \mathrm{~S}_{2}$ progeny. For the homozygous class, $19 / 20 B C_{1} S_{2}$ families confirmed the homozygous $B C_{1} S_{1}$ prediction while $21 / 21 B_{1} S_{1}$ families confirmed the hemizygous prediction of the original parent. This relatively simple protocol provides a reliable, rapid, and high-throughput way of evaluating segregating transgenic populations using methods and equipment common to crop molecular breeding labs.

Keywords: transgene, PCR, bimodal, method, plant breeding, cotton 


\section{INTRODUCTION}

Cotton (Gossypium spp.) continues to be the basic resource for thousands of consumer and industrial products manufactured in the world, and its contribution to the fiber and food industry continues to grow in importance. The simultaneous improvement of fiber quality and yield in Upland cotton (G. hirsutum L.) has long been a challenging objective for many public and private breeding programs. In a recent study, the RNAi-mediated silencing of the G. hirsutum phytochrome A1 gene (PHYA1) resulted in a substantial improvement in fiber length and other fiber characteristics (Abdurakhmonov et al., 2014). In these experiments, RNAi was accomplished via expression of a PHYA1 hairpin using the pHellsgate- 8 binary vector (Abdurakhmonov et al., 2014). Given the potential for this technology to dramatically 'fast-forward' long standing cotton improvement goals, our research group has endeavored to determine the effects of the pHellsgate-8::PHYA1 RNAi construct in a variety of genetic backgrounds that had been developed specifically for United States cotton production. To accomplish this task, a backcross breeding program was initiated whereby the transgenic event E-1-7-6 was used as a parent in crosses with nine United States cultivars. To be successful, we must be able to not only track the pHellsgate-8::PHYA1 RNAi construct in subsequent generations but also determine the homozygosity or hemizygosity of individual progeny in the $\mathrm{BC}_{1} \mathrm{~S}_{1}$ generation and other downstream segregating generations.

A variety of methods have been developed that can distinguish between homozygous and hemizygous alleles at a particular locus. Quantitative real-time PCR (qPCR) combines amplification and detection in a single step and offers the possibility of simultaneous amplification of the segment of interest and measurement of the amount of resulting DNA molecules through reaction cycles (Heid et al., 1996). Due to its high level of sensitivity, qPCR has been successfully used to determine transgene copy number in transgenic maize (Shou et al., 2004), rice (Yang et al., 2005), and wheat (Li et al., 2004). qPCR has also been used to identify homozygous transgenic plants at a single locus and in tracking multiple transgenes (Wang et al., 2015). While the success of qPCR to track transgene zygosity has been demonstrated, the procedure itself is technically challenging and requires relatively expensive consumables. Methods similar to qPCR such as thermal asymmetric interlacedPCR (TAIL-PCR; Liu et al., 1995) and, more recently, digital droplet PCR (ddPCR) (Hindson et al., 2011) have been used to provide information about the integration status of a transgenic allele(s) in genomes (Larkan et al., 2016). ddPCR is considered an appropriate method for zygosity testing due to its reliable and highly consistent results (Glowacka et al., 2016; Passricha et al., 2016). However, these processes are still labor intensive and less well suited for automation, which may be classified as costly procedures and/or lower throughput strategies (Zhang et al., 2015). Next generation sequencing (NGS) is advantageous because there is no need to normalize the PCR for producing robust zygosity data, which could be a tool for high-throughput transgenic genotype identification. However, this assay requires that the exact integration site of the transgene is known including adjacent genomic sequences, and it is unclear whether NGS would be suitable for tetraploid and hexaploid crops. In such cases, the PCR equalization and the normalization of reads may once again become necessary (Fritsch et al., 2015).

PCR products generated using standard amplification protocols can be detected through gel electrophoresis or capillary array electrophoresis technology. Capillary electrophoresis allows recognizing the specific PCR yield of a reaction via measurement of the peak height and/or peak area. We hypothesized that a determination of transgene zygosity in an individual could be accomplished using standard PCR of transgene-specific target sites if product yield was analyzed during the logarithmic phase of amplification. In this report, we provide an optimized protocol for determining transgene zygosity in segregating plant populations using an abbreviated standard PCR program of 10 cycles followed by product analysis via capillary electrophoresis and statistical analyses of product peak height and peak area. This simple, rapid, reliable and high-throughput technique would be accessible to the majority of crop molecular breeding laboratories.

\section{MATERIALS AND METHODS}

\section{Plant Materials}

The RNAi-PHYA1 transgenic event 'E-1-7-6' was used in this study. E-1-7-6 carries the pHellsgate-8::PHYA1 RNAi construct (Abdurakhmonov et al., 2014). In addition, the G. hirsutum line Coker-312 (genetic background of E-1-7-6) and two transgenenull sibling lines of E-1-7-6 (Null Seg 1-7 and Null Seg 31-10) were used in this study. These lines, along with E-1-7-6, were planted in the USDA-ARS greenhouse at Mississippi State, MS for genotyping protocol development. All greenhouse and field experiments that included line E-1-7-6 or its derivatives were performed under APHIS permit number 16-049-107r.

As part of an ongoing project to determine the effects of the pHellsgate-8::PHYA1 RNAi construct in a variety of genetic backgrounds, six G. hirsutum cultivars and three germplasm breeding lines were used in a backcross program (Table 1). Two-hundred-forty individuals of each $\mathrm{BC}_{1} \mathrm{~S}_{1}$ population along with E-1-7-6, transgene-null sibling lines, and Coker-312 were grown in the field at Mississippi State, MS for transgene genotyping. Confirmation of $\mathrm{BC}_{1} \mathrm{~S}_{1}$ plant transgene zygosity was

TABLE 1 | Germplasm used for back-crossing to the E-1-7-6 transgenic line.

\begin{tabular}{lll}
\hline Genotype & PI or PVP No. & Developer \\
\hline Coker312 & PI 529278, PVP 7200100 & Coker's Pedigreed Seed Co. \\
DP90 & PI 529529 & Delta \& Pine Land Co. \\
SG747 & PI 656375 & Sure-Grow Seed, Inc. \\
PSC355 & PI 612974 & Phytogen Seed Company, LLC \\
FM966 & PVP 200100209 & Bayer CropScience Co. \\
UA222 & PI 664929 & University of Arkansas \\
TAM B182-33 & PI 654362 & Texas A\&M University \\
MD51ne & PI 566941 & William R. Meredith Jr., USDA-ARS \\
MD90ne & PI 634931 & William R. Meredith Jr., USDA-ARS
\end{tabular}



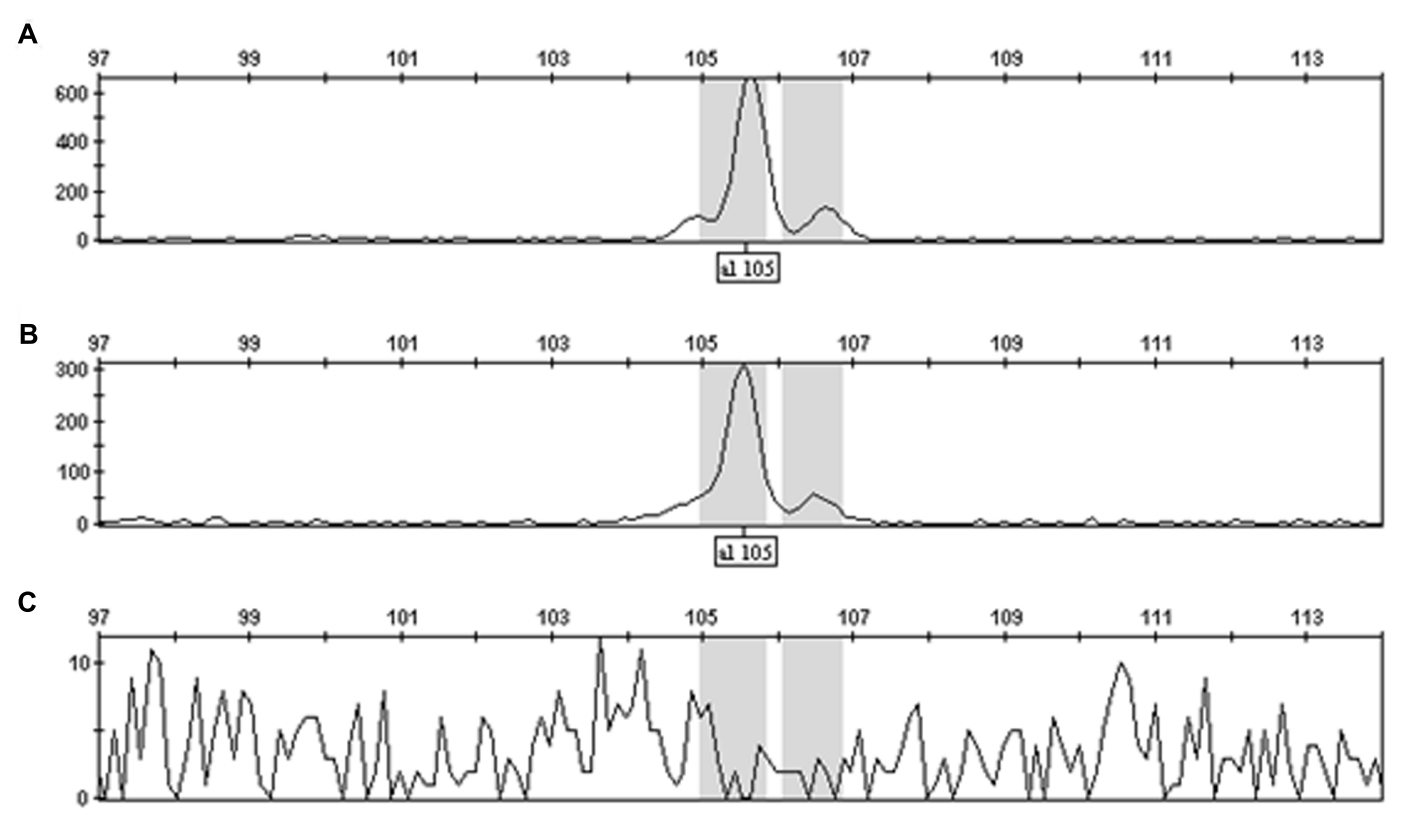

FIGURE 1 | GeneMapper ${ }^{T M}$ display of OCS_S PCR product peak heights for plants homozygous (A), hemizygous (B), or null (C) for the pHellsgate-8::PHYA1 RNAi construct. Note the change in scale between (A) and (B).

accomplished by testing for transgene segregation in $488 \mathrm{BC}_{1} \mathrm{~S}_{2}$ progenies derived from 21 hemizygous $B_{1} S_{1}$ plants and 456 $\mathrm{BC}_{1} \mathrm{~S}_{2}$ progenies derived from 20 homozygous $\mathrm{BC}_{1} \mathrm{~S}_{1}$ plants.

\section{Genomic DNA Extraction}

A single $10 \mathrm{~mm}$-diameter leaf punch was taken from a young leaf and collected into a $1.5 \mathrm{~mL}$ centrifuge tube. DNA was extracted directly from the fresh tissue using the DNeasy 96 Plant Kit (QIAGEN, Valencia, CA, United States) per the manufacturer's instructions with the following modifications: (i) sodium metabisulfite was added to the lysis buffer to a final concentration of $10 \mathrm{mM}$ from a freshly prepared $1 \mathrm{M}$ stock solution (Horne et al., 2004) and (ii) the incubation time in lysis buffer at $65^{\circ} \mathrm{C}$ was increased to $45 \mathrm{~min}$. All DNA extractions were performed using a Microlab Star robot (Hamilton, Reno, NV, United States). Genomic DNA quality and quantity were measured using a Synergy HT plate reader with Gen5 2.06 application software (BioTek, Winooski, VT, United States). All DNA samples were normalized to a concentration of $5 \mathrm{ng} / \mu \mathrm{L}$ using the Microlab Star robot to serve as template in subsequent PCR (polymerase chain reaction) experiments.

\section{PCR Primer Design}

PCR primer pair sequences were designed that targeted three regions of the pHellsgate-8::PHYA1 RNAi T-DNA sequence. These primer pairs amplified portions of the following vector components: the CaMV 35S promoter (35S_S; forward 5' -GCTC CTACAAATGCCATCATTG-3', reverse 5'-CTTGCTTTGAAG ACGTGGTTG-3'), the octopine synthase terminator (OCS_S; forward 5'-CTGCTTTAATGAGATATGCGAGAC-3', reverse $5^{\prime}$-CGGTAAGGATCTGAGCTACAC-3'), and the neophospho- transferase resistance gene (NPTII-3; forward 5'-CTGCCGA GAAAGTATCCATCAT-3', reverse 5'-GATCATCCTGATCGAC AAGACC- $3^{\prime}$ ). All primers were designed using the PrimerQuest online tool available at www.idtdna.com. Primer sequences specific to GhUBC1 were synthesized according to Yi et al. (2008). To perform multiplex PCR, the $5^{\prime}$-end of all forward primers were labeled with different fluorescent dyes compatible with the ABI PRISM 3130xl Genetic Analyzer ${ }^{\mathrm{TM}}$ (Applied Biosystems, Foster City, CA, United States).

\section{PCR for Transgene Zygosity Determination}

PCR reactions for 96-well plates were performed in a total volume of $10 \mu \mathrm{L}$ using $12.5 \mathrm{ng}$ of DNA as template. For 384well plates, a total volume of $5 \mu \mathrm{L}$ was used along with 6.25 ng of DNA template. The final concentrations of the remaining reaction components were as follows unless otherwise noted: $0.15 \mu \mathrm{M}$ primer, $0.05 \mathrm{mM}$ each dNTP, 1x GeneAmp PCR Gold Buffer (Applied Biosystems), 1\% (w/v) PVP (10,000 mw, Sigma, St. Louis, MO, United States), 0.05 units AmpliTaq Gold DNA polymerase (Applied Biosystems), and 3.0 - $4.0 \mathrm{mM} \mathrm{MgCl}_{2}$. PCR amplification was carried out using a DNA Engine Tetrad ${ }^{\circledR} 2$ Thermal Cycler (Bio-Rad, Hercules, CA, United States). All reactions were performed with an initial $7 \mathrm{~min}$ incubation at $95^{\circ} \mathrm{C}$ followed by a touchdown protocol of 14 cycles of $94^{\circ} \mathrm{C}$ for $15 \mathrm{~s}, 65^{\circ} \mathrm{C}$ for $30 \mathrm{~s}$ (decreasing by $0.7^{\circ} \mathrm{C}$ with each cycle), and $72^{\circ} \mathrm{C}$ for $1 \mathrm{~min}$. After the touchdown protocol, amplification was accomplished using the following program: $\left(94^{\circ} \mathrm{C}\right.$ for $15 \mathrm{~s}$, $55^{\circ} \mathrm{C}$ for $30 \mathrm{~s}$, and $72^{\circ} \mathrm{C}$ for $\left.1 \mathrm{~min}\right) \times 5,10,15,20,30$, or 40 cycles. All reactions were subjected to a final incubation at $72^{\circ} \mathrm{C}$ for $30 \mathrm{~min}$. PCR product visualization was accomplished using 


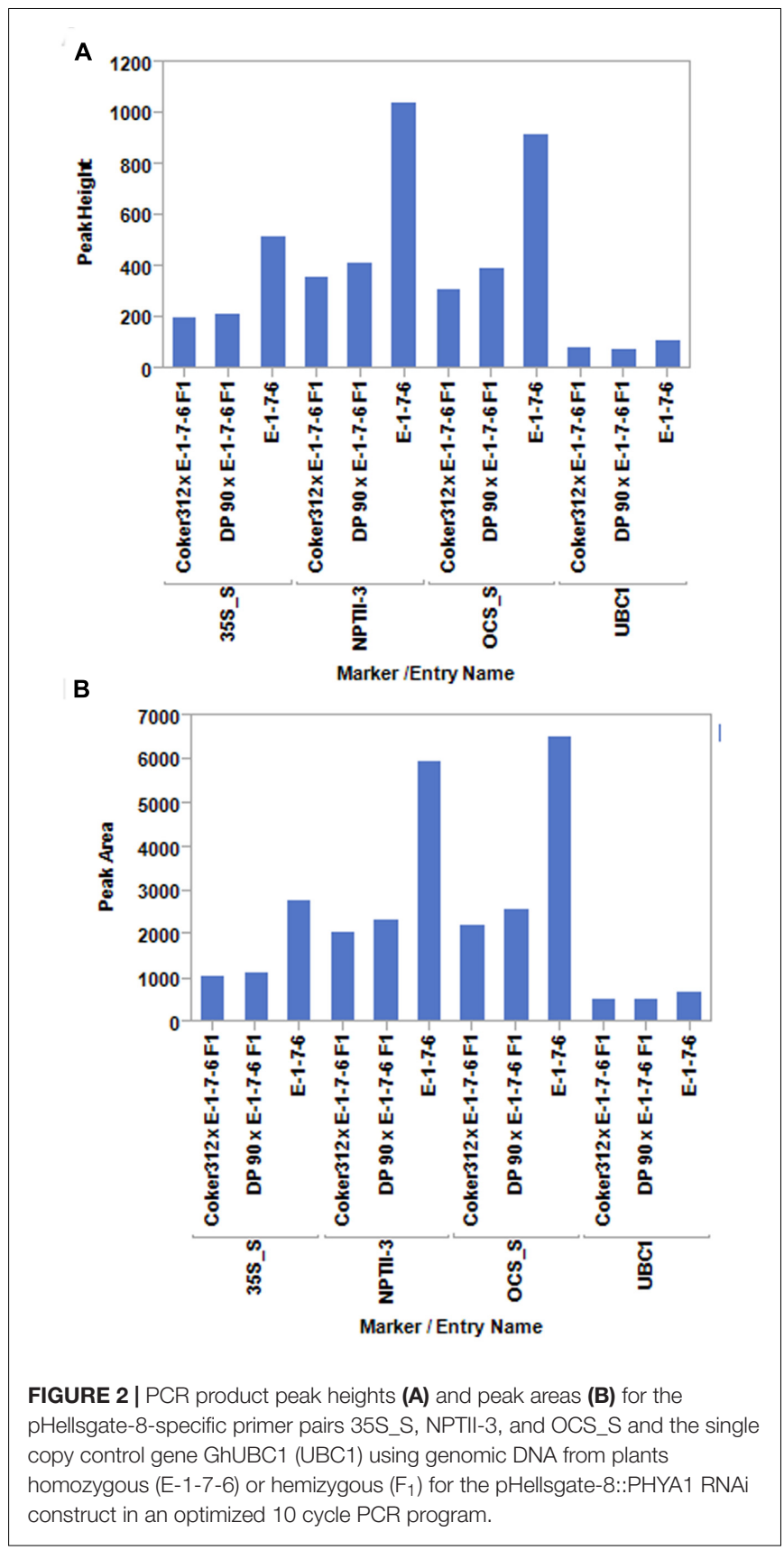

the automated ABI PRISM 3130 Genetic Analyzer ${ }^{\text {TM }}$ according to manufacturer's protocol on a Genetic Analyzer 3130xl. Raw data was analyzed using GeneMapper ${ }^{\mathrm{TM}} 4.1$ software (Applied Biosystems). PCR products were characterized quantitatively by the size of the amplicon in base pairs, amplicon peak height, and amplicon peak area. These characteristics (i.e., amplicons size, peak height, and peak area) are considered 'traits' for each primer pair used in the current study.

\section{Data Analysis}

Peak height and area values, i.e., traits, generated by the 35S, OCS, and NPTII primer pairs were normalized using the corresponding values given by GhUBC1 amplification. GhUBC1 is a verified single copy gene in G. hirsutum (Zhang et al., 2003) and its trait values for a given sample would help to minimize sample-to-sample variation. Trait data normalization was conducted by the statistical conversion:

$$
T=(X / Y)^{*} Z
$$

Where, $T=$ normalized trait value of 35 S, OCS, or NPTII PCR product;

$X=$ Original trait value of 35 S, OCS, or NPTII PCR product;

$Y=$ Original trait value of GhUBC1 PCR product;

$Z=$ Population median of the trait value of GhUBC1

PCR product. The median trait value was employed because of possible non-normal distribution nature of a population.

The population distribution, trait correlation, and entry cluster analysis for all $\mathrm{BC}_{1} \mathrm{~S}_{1}$ populations were determined using JMP Genomics 6.0 (SAS Institute, Raleigh, NC, United States). To discriminate between transgene homozygous and hemizygous individuals within each segregating $\mathrm{BC}_{1} \mathrm{~S}_{1}$ population, two clustering approaches were employed. First, the presence of transgene homozygous and hemizygous individuals in a population would create a bimodal distribution of individuals. The valley, or 'pit', separating the modes was used to group

TABLE 2 | Segregation of the pHellsgate-8::PHYA1 construct in nine $\mathrm{BC}_{1} \mathrm{~S}_{1}$ populations.

\begin{tabular}{|c|c|c|c|c|}
\hline $\mathrm{BC}_{1} \mathrm{~S}_{1}$ population & $\begin{array}{l}\text { Transgenic } \\
\text { plants }^{\mathrm{a}}\end{array}$ & $\begin{array}{c}\text { Null } \\
\text { plants }^{\mathrm{b}}\end{array}$ & $\begin{array}{c}\text { Missing } \\
\text { data }^{c}\end{array}$ & Total \\
\hline Coker312 & 160 & 68 & 12 & 240 \\
\hline DP90 & 158 & 66 & 16 & 240 \\
\hline SG747 & 171 & 48 & 21 & 240 \\
\hline PSC355 & 162 & 56 & 22 & 240 \\
\hline FM966 & 174 & 60 & 6 & 240 \\
\hline UA222 & 170 & 66 & 4 & 240 \\
\hline TAM B182-33 & 179 & 56 & 5 & 240 \\
\hline MD51ne & 181 & 49 & 10 & 240 \\
\hline MD90ne & 159 & 58 & 23 & 240 \\
\hline Total & 1514 & 527 & 119 & 2160 \\
\hline
\end{tabular}

aSuccessful amplification of the 35S_S, OCS_S, and NPTII-3 target sequences. bSuccessful amplification of only the GhUBC1 target sequence. 'Missing due to non-amplification or aberrant amplification of target sequences.

TABLE 3 | Correlations between 35S, OCS, and NPTII PCR product peak heights and peak areas.

\begin{tabular}{lccccc}
\hline & $\begin{array}{c}\text { OCS } \\
\text { height }\end{array}$ & $\begin{array}{c}\text { NPTII } \\
\text { height }\end{array}$ & $\begin{array}{c}\text { 35S } \\
\text { area }\end{array}$ & $\begin{array}{c}\text { OCS } \\
\text { area }\end{array}$ & $\begin{array}{c}\text { NPTII } \\
\text { area }\end{array}$ \\
\hline 35S height & $0.849^{*}$ & 0.492 & $0.991^{*}$ & $0.835^{*}$ & 0.497 \\
OCS height & & 0.426 & $0.821^{*}$ & $0.933^{*}$ & 0.423 \\
NPTII height & & & 0.480 & 0.392 & $0.997^{*}$ \\
35S area & & & & $0.825^{*}$ & 0.492 \\
OCS area & & & & & 0.395 \\
\hline
\end{tabular}

*Statistically significant at $P \leq 0.05$. 

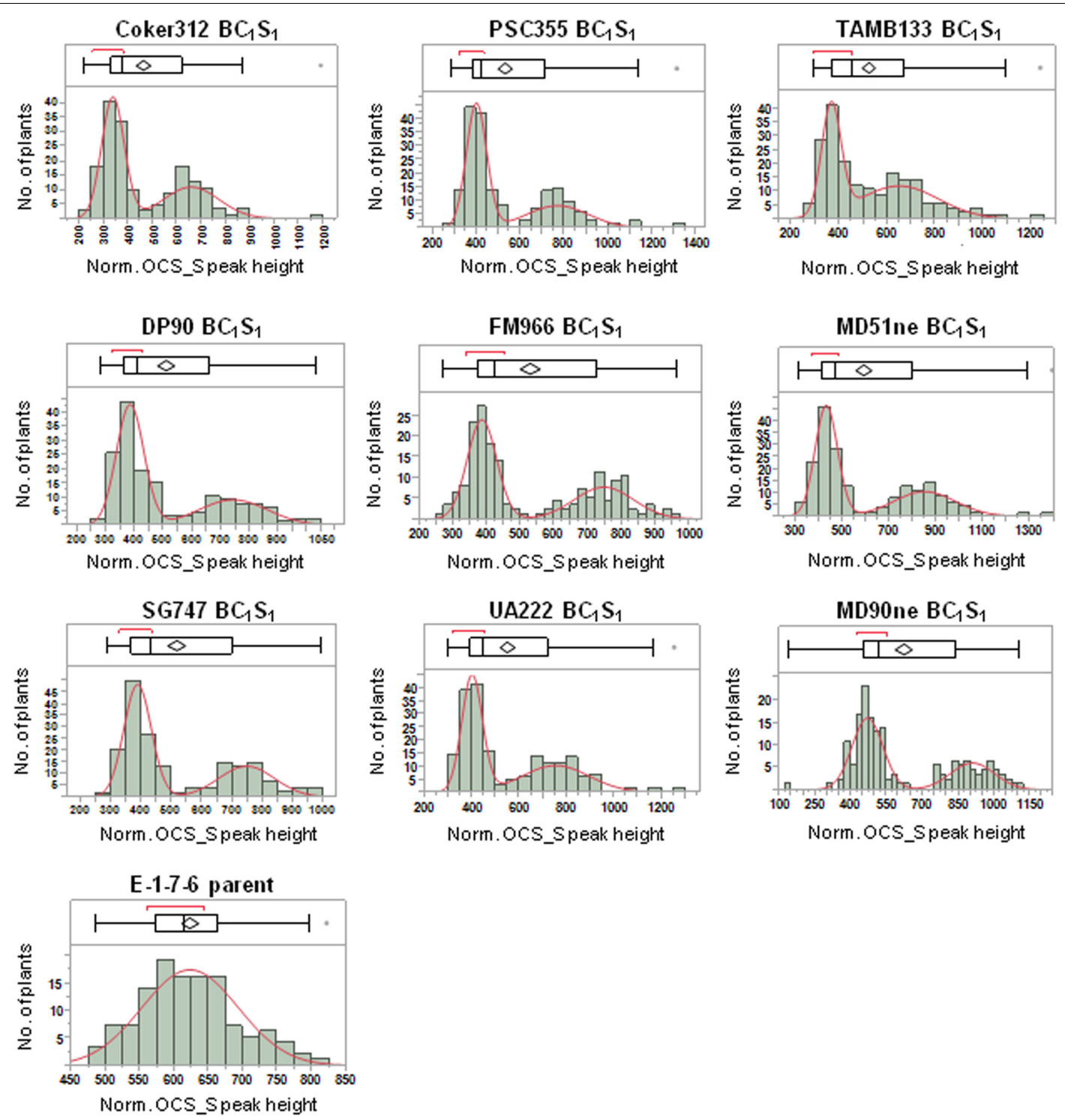

FIGURE 3 | Distributions of normalized OCS_S PCR product peak height values for nine $\mathrm{BC}_{1} \mathrm{~S}_{1}$ populations derived from crosses between non-transgenic cultivars and the E-1-7-6 line homozygous for the pHellsgate-8::PHYA1 RNAi construct. The boxplot above each histogram shows selected quantiles of continuous distributions and outliers.

the individuals into zygosity classes. The second method used K-Means clustering with two clusters as default for multivariable analysis based on particular trait values for the 35S, OCS, or NPTII PCR products. The Tukey-Kramer HSD (honest significant difference) was used as significance test for two separated groups identified by K-Means clustering. The K-Means approach to clustering performs an iterative alternating fitting process to form the number of specified clusters and assign points to the closest clusters, which is a special case of a general approach called the EM (expectation maximization) algorithm. Due to expected unequally sized clusters, the points give preference to being assigned to the larger cluster; therefore, CCC (Cubic Clustering Criterion) was used to evaluate the model as a good fit if it was greater than or equal to 2
(Hartigan, 1985). The 'goodness of fit' of an observed genotypic class distribution in a $\mathrm{BC}_{1} \mathrm{~S}_{1}$ population to the $1: 2: 1$ ration was tested by the likelihood ratio and Pearson Chi-square tests.

\section{RESULTS AND DISCUSSION}

\section{Optimization of PCR Parameters}

The optimization of the pHellsgate8-specific primer pairs 35S_S, OCS_S, and NPTII-3 centered on manipulating the following parameters: (i) final concentration of $\mathrm{MgCl}_{2}$ in the PCR reaction, (ii) number of amplification cycles in the PCR program, and (iii) single versus multiplex PCR. For these experiments genomic 
TABLE 4 | Transgene zygosity in $\mathrm{BC}_{1} \mathrm{~S}_{1}$ populations determined by K-means clustering of normalized OCS_S PCR product peak heights and areas.

\begin{tabular}{|c|c|c|c|c|c|c|c|}
\hline \multirow[b]{2}{*}{ Population } & \multicolumn{3}{|c|}{ Homozygous } & \multicolumn{3}{|c|}{ Hemizygous } & \multirow[b]{2}{*}{${ }^{\mathrm{a}} \mathrm{CCC}$} \\
\hline & No. plants & Peak height & Peak area & No. plants & Peak height & Peak area & \\
\hline Coker312 & 57 & 678.2 & 4426.7 & 103 & 344.4 & 2315.4 & 3.57 \\
\hline DP90 & 50 & 766.6 & 4587.8 & 108 & 389.7 & 2556.1 & 7.32 \\
\hline SG747 & 58 & 757.7 & 4271.2 & 113 & 394.0 & 2471.4 & 8.31 \\
\hline PSC355 & 52 & 796.7 & 5177.6 & 110 & 405.6 & 2676.8 & 4.22 \\
\hline FM966 & 64 & 760.0 & 5296.2 & 110 & 395.4 & 2868.4 & 7.76 \\
\hline UA222 & 62 & 788.6 & 5461.5 & 108 & 414.2 & 3044.1 & 4.63 \\
\hline TAM B182-33 & 63 & 740.1 & 4961.6 & 116 & 405.4 & 2885.3 & 2.02 \\
\hline MD51ne & 66 & 862.3 & 3018.0 & 115 & 436.7 & 3190.3 & 6.93 \\
\hline MD90ne & 55 & 910.9 & 6440.9 & 104 & 469.2 & 3390.7 & 8.26 \\
\hline Average & 59 & 784.6 & 5182.4 & 110 & 406.1 & 2822.1 & 5.89 \\
\hline
\end{tabular}

aCubic Clustering Criterion was used to evaluate model (CCC $\geq 2.00$ means model is good fit for data).

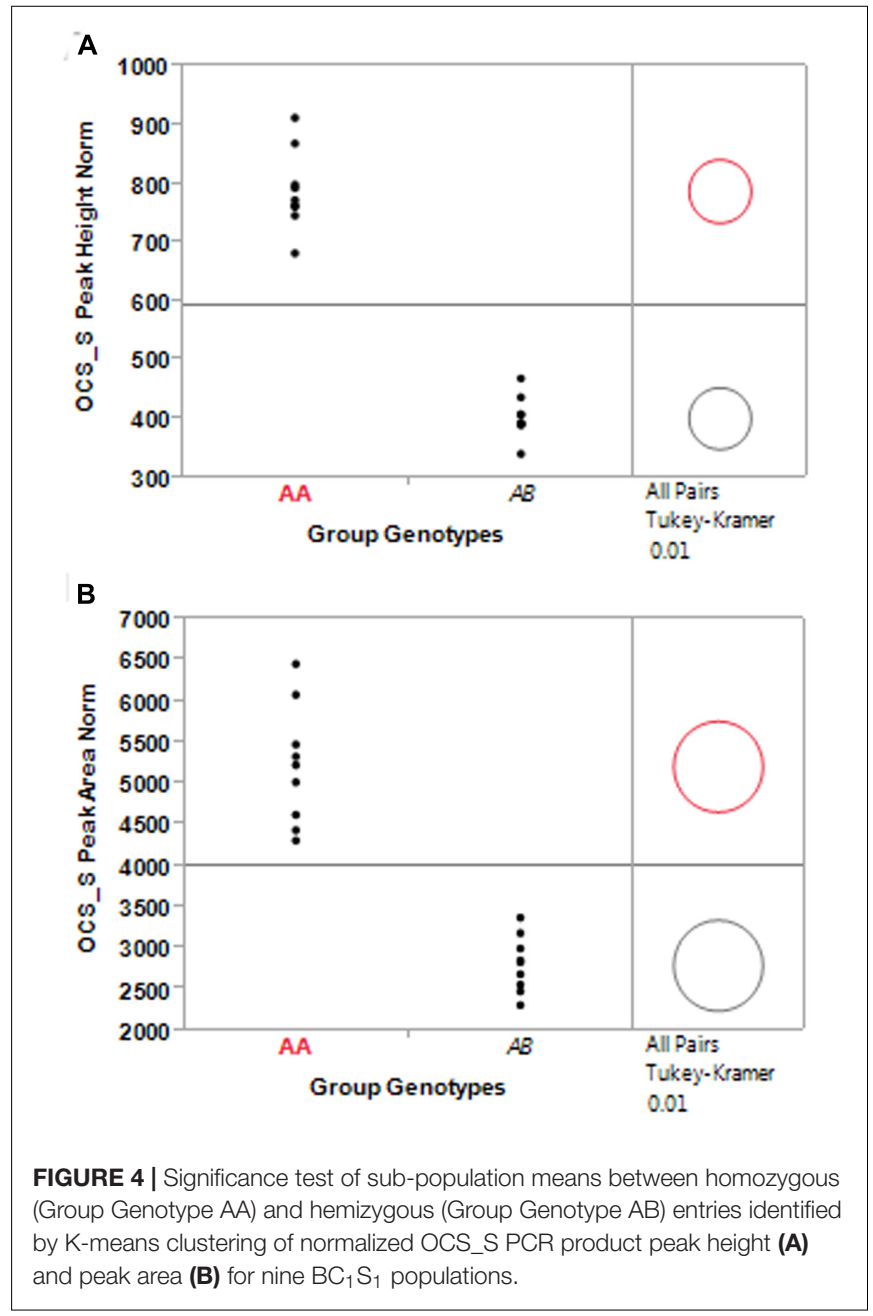

DNA from a Coker312 $\times$ E-1-7-6 $\mathrm{F}_{1}$ plant was used as a hemizygous transgenic control while DNA from E-1-7-6 plants served as a homozygous transgenic control. For a negative control genomic DNA from a transgenic-null sibling line of E-1-7-6 was used as template.
These experiments were initiated under the premise that the amplification of a target site within the pHellsgate8 T-DNA would result in differing amounts of final product being produced depending on if the T-DNA was in a hemizygous versus homozygous state. To determine the validity of this premise 35S_S, OCS_S, and NPTII-3 primers were run separately on hemizygous, homozygous, and null DNA templates using PCR programs having 5, 10, 15, 20, 30, or 40 cycles. Regardless of primer, programs having only five cycles did not produce sufficient amounts of product for detection by capillary electrophoresis (data not shown). PCR programs of 20,30, or 40 cycles produced roughly the same amount of product regardless of primer and starting template, i.e., hemi- or homozygous. In contrast, PCR programs having 10 cycles consistently generated product amount ratios, calculated from peak height and peak area values, of $\sim 0.50$ for hemizygous product/homozygous product for the 35S_S and OCS_S primer pairs (Figure 1 and Supplementary Table S1). The dilution level of PCR product prior to capillary electrophoresis, ranging from undiluted to $15 \times$ dilution, did not affect the ability of these primers to discriminate between hemi- and homozygous transgenic plants. (Supplementary Table S1). PCR parameters were further refined by testing final $\mathrm{MgCl}_{2}$ concentrations of 3.0, 3.5, and $4.0 \mathrm{mM}$ in single reactions and in multiplex reactions where the 35S_S, OCS_S, NPTII-3, and GhUBC1 were combined. We determined that a $\mathrm{MgCl}_{2}$ concentration of $4.0 \mathrm{mM}$ in a multiplexed reaction (all four primer pairs combined) produced optimal results (Supplementary Tables S2, S3). The finalized PCR reaction conditions (10 cycles, $4.0 \mathrm{mM}$ $\mathrm{MgCl}_{2}$, multiplexed) were tested on another hemizygous transgenic DNA sample derived from a DP90 $\times$ E-1-7-6 F1 plant. The 35S_S, NPTII-3, and OCS_S primers each produced PCR product peak area and peak height ratios of $\sim 0.5$ for hemizygous versus homozygous transgene genotypes (Figure 2 and Supplementary Table S3). In contrast, the control GhUBC1 primer gave product traits that were similar regardless of starting template, thereby confirming its utility as an internal PCR control (Figure $\mathbf{2}$ and Supplementary Table S3). 
TABLE 5 | Confirmation of $\mathrm{BC}_{1} \mathrm{~S}_{1}$ transgene genotype prediction in $\mathrm{BC}_{1} \mathrm{~S}_{2}$ progeny families.

\begin{tabular}{|c|c|c|c|c|c|}
\hline $\begin{array}{l}\text { Predicted } \mathrm{BC}_{1} \mathrm{~S}_{1} \\
\text { plant genotype }\end{array}$ & $\begin{array}{c}\text { No. of selfed } \mathrm{BC}_{1} \mathrm{~S}_{1} \\
\text { plants }\end{array}$ & $\begin{array}{l}\text { No. of correct } \mathrm{BC}_{1} \mathrm{~S}_{1} \\
\text { predictions }\end{array}$ & $\begin{array}{c}{ }^{\text {a }} \text { Homozygous } \mathrm{BC}_{1} \mathrm{~S}_{2} \\
\text { plants/family }\end{array}$ & $\begin{array}{c}{ }^{\text {a }} \text { Hemizygous } \mathrm{BC}_{1} \mathrm{~S}_{2} \\
\text { plants/family }\end{array}$ & 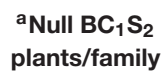 \\
\hline Homozygous & 20 & 19 & 22.5 & 0.0 & 0.0 \\
\hline
\end{tabular}

aMean number per self-fertilized $B C_{1} S_{1}$ plant. Homozygous and hemizygous classifications determined by K-means clustering of normalized OCS_S PCR product peak height values.

\section{Determination of Transgene Zygosity in Segregating $B C_{1} S_{1}$ Populations}

Nine $B_{1} S_{1}$ populations were created from crosses made between E-1-7-6 and the nine genotypes listed in Table 1. A total of 240 plants from each population were genotyped using the 35S_S, OCS_S, and NPTII-3 primers using the optimized PCR and electrophoresis protocol described above. The single copy internal control GhUBC1 primer was also run on each sample. Only those samples that were successfully amplified with each transgene primer were considered 'transgenic' and included in downstream zygosity analyses. Samples that produced a PCR product with only the GhUBC1 primer were considered to be transgene-null.

In each $\mathrm{BC}_{1} \mathrm{~S}_{1}$ population the numbers of transgenic and null plants indicated the pHellsgate-8::PHYA1 construct segregated as a single locus (i.e., a 3:1 ratio of transgenic to null plants) (Table 2). In this study, PCR product peak heights and areas were highly correlated for the 35S_S and OCS_S primer pairs, indicating similar efficiencies in target site amplification (Table 3). In contrast, NPTII-3 did not amplify consistently across all $\mathrm{BC}_{1} \mathrm{~S}_{1}$ populations and its product characteristics were not correlated with those of 35S_S and OCS_S (Table 3).

The successful discrimination between transgene homozygous and hemizygous plants would manifest as a bimodal distribution of normalized PCR product values in a $\mathrm{BC}_{1} \mathrm{~S}_{1}$ population where each peak in the distribution would represent a distinct genotype. A bimodal distribution is a mixture of two normal distributions with means ( $\mu 1$ and $\mu 2$ ) and standard deviations ( $\sigma 1$ and $\sigma 2)$; therefore, the distributions of normalized PCR product peak height and area values for 35S_S, OCS_S, and NPTII-3 were analyzed for each of the nine $\mathrm{BC}_{1} \mathrm{~S}_{1}$ populations. A clear bimodal distribution of normalized peak height values was readily apparent for the OCS_S primer in each $\mathrm{BC}_{1} \mathrm{~S}_{1}$ population (Figure 3). In each population a clear demarcation between the mode peaks is observed. This demarcation is observed as a region of low observation frequency and is called the 'pit.' The pit provides a natural split point to cluster the homozygous and hemizygous genotypic classes. In contrast to the $\mathrm{BC}_{1} \mathrm{~S}_{1}$ populations, a survey of 125 E-1-7-6 plants showed a normal distribution of normalized OCS_S peak heights (Figure 3). The 35S_S and NPTII-3 primers did not produce clear bimodal distributions for each $\mathrm{BC}_{1} \mathrm{~S}_{1}$ population (data not shown). This was most likely due to decreased robustness in PCR efficiency of these primers from sample to sample.

In addition to using the bimodal natural split to cluster entries in each population, a K-Means clustering analysis with $k=2$ was conducted as well (Table 4). The criterion function of the
$\mathrm{K}$-means algorithm is the squared distance of the data items from their nearest cluster centroids. The mean normalized OCS_S PCR product peak height, across all nine $\mathrm{BC}_{1} \mathrm{~S}_{1}$ populations, was 784.6 for the homozygous group and 406.1 for the hemizygous group. A similar relationship was observed for the mean normalized peak area (homozygous $=5182.4$; hemizygous $=2822.1$ ) (Table 4). When analyzed individually, the grouping of the population peak height and area means according to homozygous and hemizygous status was statistically significant (Figure 4). Out of 1514 plants classified as transgenic, we found only 45 instances where the bimodal natural split and K-Means clustering methods disagreed in identifying a particular sample as homozygous or hemizygous. Using the K-Means clustering analysis to identify transgene homozygous and hemizygous plant allowed us to determine that the pHellsgate-8::PHYA1 construct segregated as a single locus in each $\mathrm{BC}_{1} \mathrm{~S}_{1}$ population. In each population the numbers of homozygous, hemizygous, and transgene-null plants fit a 1:2:1 ratio that was significant according to Chi-square analysis (data not shown).

\section{Confirmation of Transgenic $\mathrm{BC}_{1} \mathrm{~S}_{1}$ Zygosity in $\mathrm{BC}_{1} \mathrm{~S}_{2}$ Progeny}

$\mathrm{BC}_{1} \mathrm{~S}_{1}$ plants identified as transgene homozygous or hemizygous were self-fertilized to produce $B_{1} S_{2}$ populations for progeny testing with the 35S_S, OCS_S, and NPTII-3 primers. Of 20 homozygous $\mathrm{BC}_{1} \mathrm{~S}_{1}$ plants selected, only one showed progeny that segregated for the pHellsgate-8::PHYA1 construct with the remaining $19 \mathrm{BC}_{1} \mathrm{~S}_{2}$ populations showing no construct segregation (Table 5). Of $21 \quad \mathrm{BC}_{1} \mathrm{~S}_{1}$ plants identified as hemizygous, all $21 \mathrm{BC}_{1} \mathrm{~S}_{2}$ populations showed a 1:2:1 segregation of the pHellsgate-8::PHYA1 construct (Table 5). Furthermore, we again observed the roughly double in value of normalized peak height and area values for homozygous plants versus hemizygous plants (Supplementary Table S4). When the normalized OCS_S product peak height values of each individual $\mathrm{BC}_{1} \mathrm{~S}_{2}$ population were visualized by histogram, a bimodal distribution pattern was observed indicating the presence of homozygous and hemizygous plants (Figure 5). Almost without exception, a clear separation was observed between the transgene homozygous and hemizygous groups (Figure 5). These results demonstrate a predictive success of $95 \%$ for transgene homozygous $\mathrm{BC}_{1} \mathrm{~S}_{1}$ plants and $100 \%$ for hemizygous plants.

\section{CONCLUSION}

Biotechnology holds great promise in overcoming many obstacles that face modern agriculture. Observing the behavior of a 

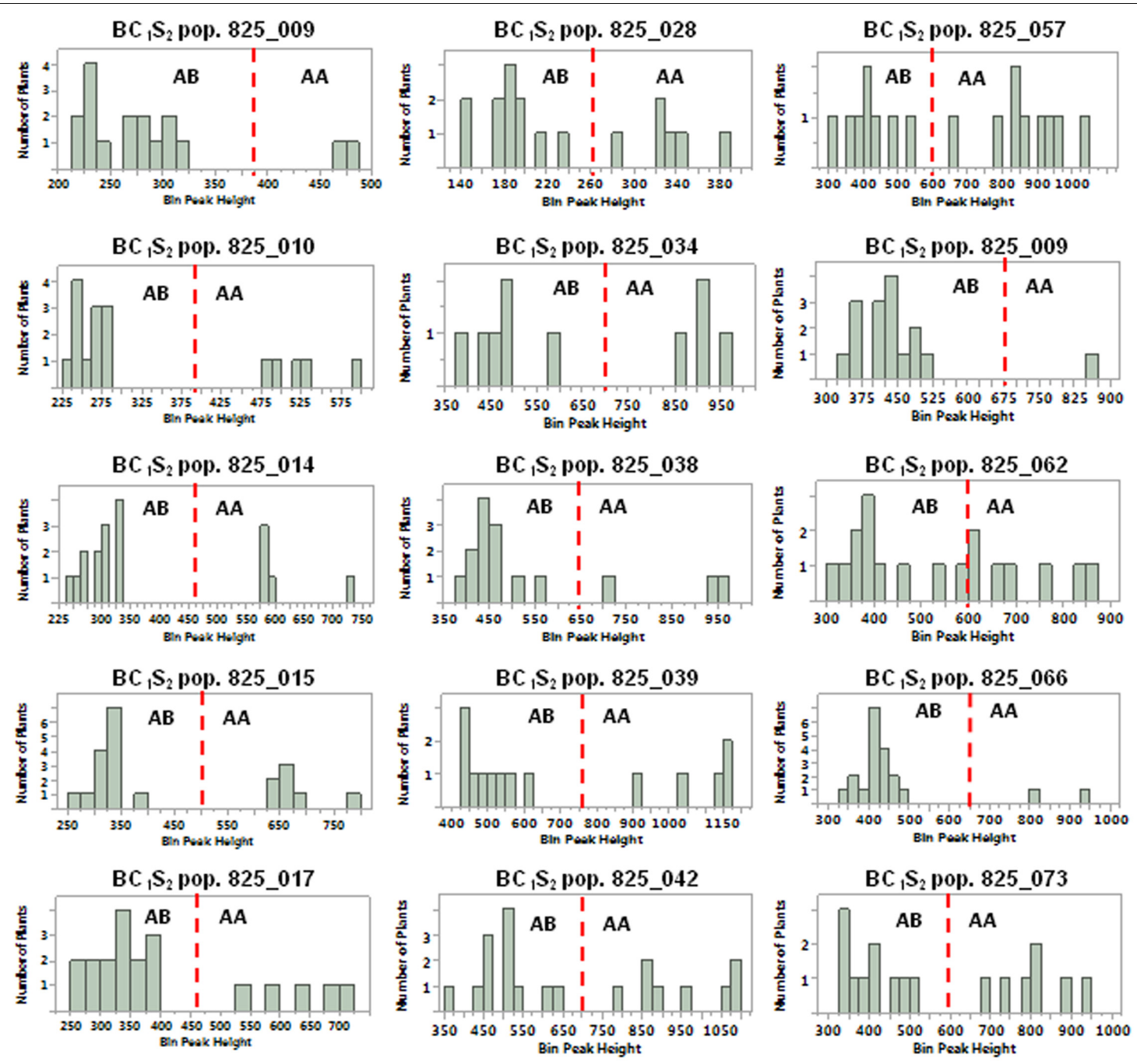

$\mathrm{BC}_{1} \mathrm{~S}_{2}$ pop. 825_021

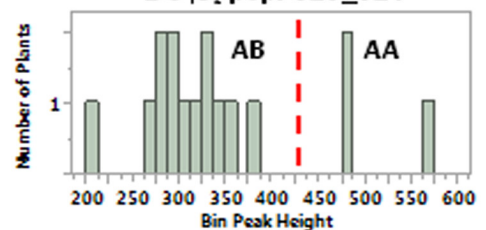

BC $S_{2}$ pop. 825_043
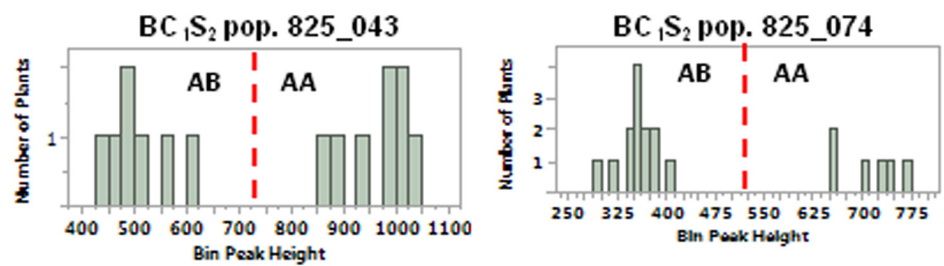

$\mathrm{BC}_{1} \mathrm{~S}_{2}$ pop. 825_021
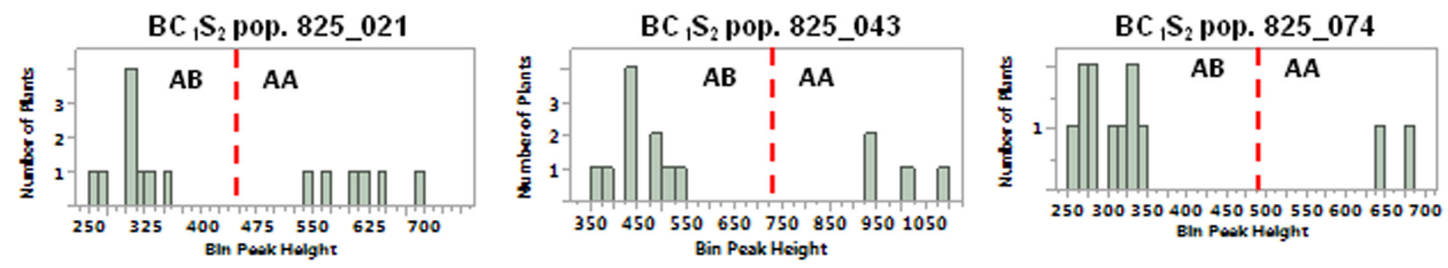

FIGURE 5 | Distribution of normalized OCS_S PCR product height values for $\mathrm{BC}_{1} \mathrm{~S}_{2}$ populations derived from $\mathrm{BC}_{1} \mathrm{~S}_{1}$ plants predicted to be hemizygous for the pHellsgate-8::PHYA1 RNAi construct. The red-dotted line in each histogram demarcates between hemizygous (AB) and homozygous (AA) progeny plants in each $\mathrm{BC}_{1} \mathrm{~S}_{2}$ population.

particular transgene in different genetic backgrounds of the target crop is a major step in trait development. Toward that end, the discrimination between homozygous and hemizygous plants is essential. The method described in this report accomplishes this task by taking advantage of the same principles that underlie quantitative PCR; however, unlike qPCR, our method does not 
require specialized instrumentation or expensive consumables and can be readily implemented by crop breeding laboratories.

\section{AUTHOR CONTRIBUTIONS}

JJ, MW, and DD planned the experiment. LG, DD, and JM collected data. LG, DD, and MW interpreted data. LG, DD, and MW wrote the manuscript. IA developed and provided the original E-1-7-6 transgenic line.

\section{FUNDING}

This project was conducted under USDA-ARS project 606421000-014-00D and supported by a grant from Cotton Incorporated LLC (Award). Ms. Lige Geng's cooperation research in USDA-ARS was supported by the International Science and

\section{REFERENCES}

Abdurakhmonov, I. Y., Buriev, Z. T., Saha, S., Jenkins, J. N., Abdukarimov, A. and Pepper, A. E. (2014). Phytochrome RNAi enhances major fiber quality and agronomic traits of the cotton Gossypium hirsutum L. Nat. Commun. 5:3062. doi: 10.1038 /ncomms4062

Fritsch, L., Fischer, R., Wambach, C., Dudek, M., Schillberg, S., and Schröper, F. (2015). Next-generation sequencing is a robust strategy for the high-throughput detection of zygosity in transgenic maize. Transgenic Res. 24, 615-623. doi: 10.1007/s11248-015-9864-x

Glowacka, K., Kromdijk, J., Leonelli, L., Niyogi, K. K., Clemente, T. E., and Long, S. P. (2016). An evaluation of new and established methods to determine T-DNA copy number and homozygosity in transgenic plants. Plant Cell Environ. 39, 908-917. doi: 10.1111/pce.12693

Hartigan, J. A. (1985). Statistical theory in clustering. J. Classif. 2, 63-76. doi: 10.1007/BF01908064

Heid, C. A., Stevens, J., Livak, K. J., and Williams, P. M. (1996). Real time quantitative PCR. Genome Res. 6, 986-994. doi: 10.1101/gr.6.10.986

Hindson, B. J., Ness, K. D., Masquelier, D. A., Belgrader, P., Heredia, N. J., Makarewicz, A. J., et al. (2011). High-throughput droplet digital PCR system for absolute quantitation of DNA copy number. Anal. Chem. 83, 8604-8610. doi: 10.1021/ac202028g

Horne, E. C., Kumpatla, S. P., Patterson, K. A., Gupta, M., and Thompson, S. A. (2004). Improved protocols for high-throughput sunflower and cotton genomic DNA extraction and PCR fidelity. Plant Mol. Biol. Rep. 22, 83-84. doi: 10.1007/ BF02773352

Larkan, N. J., Ma, L., and Borhan, M. H. (2016). The Brassica napus receptorlike protein RLM2 is encoded by a second allele of the LepR3/Rlm2 blackleg resistance locus. Plant Biotechnol. J. 13, 983-992. doi: 10.1111/pbi. 12341

Li, Z., Hansen, J., Liu, Y., Zemetra, R., and Berger, P. (2004). Using real-time PCR to determine transgene copy number in wheat. Plant Mol. Biol. Rep. 22, 179-188. doi: $10.1007 / \mathrm{BF} 02772725$

Liu, Y. G., Mitsukawa, N., Oosumi, T., and Whittier, R. F. (1995). Efficient isolation and mapping of Arabidopsis thaliana T-DNA insert junctions by thermal asymmetric interlaced PCR. Plant J. 8, 457-463. doi: 10.1046/j.1365-313X.1995. 08030457.x

Passricha, N., Saifi, S., Khatodia, S., and Tuteja, N. (2016). Assessing zygosity in progeny of transgenic plants: current methods and perspectives. J. Biol. Methods 3, e46. doi: 10.14440/jbm.2016.114
Technology Cooperation Program (Project ID: 15396304D, funded by Science and Technology Department of Hebei Province, China).

\section{ACKNOWLEDGMENT}

The authors would like to thank Drs. Jinfa Zhang and Lori Hinze of New Mexico State University and USDA-ARS, respectively, for their helpful critical review of the manuscript and helpful comments.

\section{SUPPLEMENTARY MATERIAL}

The Supplementary Material for this article can be found online at: http://journal.frontiersin.org/article/10.3389/fpls.2017.01252/ full\#supplementary-material

Shou, H., Frame, B., Whitham, S., and Wang, K. (2004). Assessment of transgenic maize events produced by particle bombardment or Agrobacterium-mediated transformation. Mol. Breed. 13, 201-208. doi: 10.1023/B:MOLB.0000018767. 64586.53

Wang, X., Jiang, D., and Yang, D. (2015). Fast-tracking determination of homozygous transgenic lines and transgene stacking using a reliable quantitative real-time PCR assay. Appl. Biochem. Biotechnol. 175, 996-1006. doi: 10.1007/s12010-014-1322-3

Yang, L., Ding, J., Zhang, C., Jia, J., Weng, H., Liu, W., et al. (2005). Estimating the copy number of transgenes in transformed rice by real-time quantitative PCR. Plant Cell Rep. 23, 759-763. doi: 10.1007/s00299-004-0881-0

Yi, C. X., Zhang, J., Chan, K. M., Liu, X. K., and Hong, Y. (2008). Quantitative real-time PCR assay to detect transgene copy number in cotton (Gossypium hirsutum). Anal. Biochem. 375, 150-152. doi: 10.1016/j.ab.2007.11.022

Zhang, X. D., Jenkins, J. N., Callahan, F. E., Creech, R. G., Si, Y., McCarty, J. C., et al. (2003). Molecular cloning, differential expression, and functional characterization of a family of class I ubiquitin-conjugating enzyme (E2) genes in cotton (Gossypium). Biochim. Biophys. Acta 1625, 269-279. doi: 10.1016/ S0167-4781(02)00623-1

Zhang, Y., Liu, Y., Zhang, J., Wang, G., Wang, J., and Liu, Y. (2015). Assessment of transgene copy number and zygosity of transgenic maize overexpressing CrylIe gene with SYBR ${ }^{\circledR}$ Green qRT-PCR. In Vitro Cell. Dev. Biol. Plant 51, 125-134. doi: 10.1007/s11627-014-9658-5

Disclaimer: Mention of trade names or commercial products in this article is solely for the purpose of providing specific information and does not imply recommendation or endorsement by the United States Department of Agriculture.

Conflict of Interest Statement: The authors declare that the research was conducted in the absence of any commercial or financial relationships that could be construed as a potential conflict of interest.

Copyright (c) 2017 Geng, Deng, Wubben, Jenkins, McCarty and Abdurakhmonov. This is an open-access article distributed under the terms of the Creative Commons Attribution License (CC BY). The use, distribution or reproduction in other forums is permitted, provided the original author(s) or licensor are credited and that the original publication in this journal is cited, in accordance with accepted academic practice. No use, distribution or reproduction is permitted which does not comply with these terms. 